\title{
ECO-PERSPECTIVAS EN EDUCACIÓN AMBIENTAL
}

Steiner Valencia Vargas*

\begin{abstract}
This proyect assumes that people's opinions and images of knowledge, reality and living things, determine the formulation, design and implementation of educational proposals regarding environmental issues. There fore, the analysis and the making of these images explicit are considered fundamental to build conceptual perspectives that structure pedagogical practices about environmental issued. Conceptual perspectives that make posible as conscious and deliberate pedagogical practice, this should contribuite to the cultural transformation of the contexts where they are developed.
\end{abstract}

\section{RESUMEN}

Este trabajo considera que las opiniones y las imágenes de conocimiento, realidad y ser vivo, que poseen los sujetos, determinan la formulación, el diseño e implementación de propuestas educativas en torno a la Educación Ambiental. Desde esta perspectiva, una aproximación al análisis y explicitación de estas imágenes se asume fundamentalmente en la construcción de perspectivas conceptuales que configuren las prácticas pedagógicas ambientalistas, como prácticas conscientes y deliberadas que influyan en la transformación cultural de los contextos donde se desarrollan.

El acompañamiento con asesorías a Proyectos de Aula e Institucionales que han desarrollado estudiantes del Programa de Especialización en Docencia de las Ciencias de la Universidad Pedagógica Nacional, y Maestros de Ciencias Naturales de la Localidad 11 de Suba, así como la participación en Congresos y Simposios a nivel regional y nacional, nos muestran que, en los contextos escolares, la Educación Ambiental es vista como una forma de "sensibilización" de los estudiantes hacia los ecosistemas, y es reducida a la realización de actividades esporádicas como reciclaje de basuras, formación de clubes ecológicos, campañas de arborización, salidas de campo, implementación de cultivos hidropónicos, producción de compost y lombricultura, e inventarios de especies animales y vegetales, entre otras.

Si bien estas actividades que se desarrollan en la escuela y fuera de ella son importantes, generalmente, aparecen desarticuladas de las prácticas cotidianas y no inciden en la transformación de los imaginarios conceptuales, valorativos y actitudinales de los sujetos que participan en ellas. Creemos que esta desarticulación y no-incidencia es producto, entre otras, de aquellas concepciones que ven al ambiente y los ecosistemas como un recipiente o un escenario exterior a los sujetos humanos, ya sean para su contemplación o para su explotación.

\footnotetext{
¿ Departamento de Física, universidad Pedagógica Nacional. Steinerv@uni.pedagogica.edu.co Santa Fe de Bogotá, D.C.
} 
Por tal razón, pensamos, que desarrollar propuestas en Educación Ambiental implica construir ámbitos de reflexión que tienen que ver, en primer lugar, con la posibilidad de hacer de la noción ecosistema un problema de conocimiento de la escuela; es decir, un espacio pedagógico para la comprensión de las relaciones Hombre-Naturaleza, HombreSociedad y para la construcción de significados, conceptualizaciones y valoraciones. Y en segundo lugar, con la necesidad de poner en juego imaginarios pedagógicos, epistemológicos y disciplinares desde los cuales estudiantes y maestros orientan y dan sentido a sus prácticas cotidianas.

Estos ámbitos de reflexión están relacionados con una serie de supuestos sobre las Imágenes de Cultura y Conocimiento, de Realidad, de Ser Vivo, de Ambiente y del papel que la escuela juega en la transformación cultural de los vínculos comunidad-ciudad. Todas estas relaciones constituyen lo que denominamos Eco-Perspectivas en Educación Ambiental.

\section{PRIMERA ECO-PERSPECTIVA: IMÁGENES DE CONOCIMIENTO Y CULTURA}

Nuestra intención de abordar la imagen de conocimiento y cultura como una Ecoperspectiva, surge, de reconocer el papel que estas imágenes juegan en el desarrollo del conocimiento, así como, de distinguir en ellas diferentes connotaciones que inciden en el tipo de prácticas escolares que se privilegian.

Por otra parte, nuestra intención no se centra en definir las imágenes o en caracterizar los elementos que las determinan, sino en mostrar cómo desde ellas elaboramos opiniones sobre la naturaleza, sobre la verdad y sus formas de legitimarla, y sobre el papel que juegan en nuestras ideas acerca de cómo es el mundo, y de cómo y quienes somos nosotros mismos. En últimas, buscamos mostrar cómo las imágenes agencian unas particulares formas de relación con nuestro mundo, con nuestros congéneres y con el conocimiento y con la cultura en general.

Así, en ciertas prácticas escolares, es frecuente encontrar opiniones que conciben, en general, los conocimientos como producto de las formas de razonamiento o de organización de la evidencia empírica de hombres geniales; y la cultura, como un escenario donde estos realizan su labor.

Desde esta imagen, el conocimiento científico, por ejemplo, es considerado como verdadero, si parte de primeros principios que son simples, claros y evidentes y luego continúa con una deducción rigurosa, de tal manera que la solidez de cada paso descansa sobre la de los pasos precedentes [...] o, sí [parte] logrando evidencias experimentales y observacionales y luego generalizándolas en leyes científicas" (BENDOV Yoav: 1998, 68-89). Como podrá colegirse, esta imagen, determina unas formas de enseñanza de las ciencias que centran su atención en el desarrollo de habilidades para la deducción matemática o para el experimento en laboratorio, así como, hace que la relación maestro-estudiante se caracterice porque el primero "sabe" y en consecuencia "enseña" y el Segundo "no sabe" y en consecuencia "aprende". Desde esta imagen de conocimiento como producto se establece una relación que podemos denominar de exterioridad, así como de falta de pertenencia y de ausencia de compromiso frente a las interacciones con los espacios cotidianos.

No obstante, si se asume el conocimiento como proceso y elaboración de ideas, histórica y socialmente condicionados por los entramados de significación que configuran 
la cultura, es posible establecer unas relaciones distintas con el conocimiento, desde las cuales adquiere relevancia el papel protagónico que los individuos tienen en la transformación cultural de sus contextos.

Desde esta perspectiva, entendemos que interpretar acontecimientos, construir fenómenos y preguntas sobre el mundo, o dar respuesta a problemas, hacen parte de la actividad permanente del hombre en la cual intervienen la red de significaciones y los múltiples sentidos que configuran el ámbito cultural en el cual se realiza dicha actividad. El conocimiento aquí se entiende entonces, como la actividad permanente de un grupo social y su desarrollo, depende entonces, no sólo del conocimiento como tal, sino de la relación de este con las imágenes y con las ideologías socialmente condicionadas, que inciden directamente en su cosmovisión.

Igualmente, a la noción de la cultura como escenario, oponemos la concepción según la cual la cultura es un entramado simbólico en el que el hombre se encuentra inmerso y desde el cual da sentido, significado y valor a las relaciones que establece con la naturaleza, consigo mismo y con los demás. Este entramado simbólico tiene un carácter histórico y contextual; es decir, que los símbolos, significados y valores que los hombres comparten no son los mismos en todas las épocas, ni en todos los lugares. La cultura o deberíamos decir mejor, las culturas, aparecen así como sistemas de relaciones en donde quienes lo integran comparten una misma trama de significados. Por esta razón no podemos hablar -como algunos aún pretenden hacerlo- de LA CULTURA en términos hegemónicos o universalizantes. Cada sistema cultural (ELKANA, Y: 1983, 22) funciona como una totalidad desde donde se construyen las ideas de mundo, dios, hombre o naturaleza; desde donde se inventan los sueños, los temores, las aspiraciones o las frustraciones; desde donde se configuran las colectividades y las identidades; desde donde se construyen los saberes y los conocimientos y desde donde en últimas se fabrica una particular idea de realidad. La cultura es entonces lo que el hombre hace; es decir las actividades que grupos humanos particulares realizan, desde los imaginarios simbólicos que los caracterizan,

\section{SEGUNDA ECO-PERSPECTIVA: IMÁGENES DE REALIDAD Y REPRESENTACIONES DE LO VIVO}

Al igual que las Imágenes de Conocimiento y Cultura agencian unas determinadas prácticas escolares, las imágenes de Realidad configuran unas determinadas representaciones sobre los seres vivos. Históricamente es posible identificar diferentes representaciones sobre los seres vivos que se corresponden con unas determinadas imágenes de realidad.

La interpretación de dichas representaciones permite aproximarse a la comprensión tanto de las imágenes de realidad que las han hecho posible como de las distintas formas de relación Hombre-Hombre, Hombre-Naturaleza que desde ellas se establecen.

Veamos cómo la "lectura" de ciertas representaciones pictóricas da cuenta de las imágenes de realidad que subyacen en ella, al igual que la "lectura" de algunas iconografías sobre los seres vivos da cuenta de las representaciones que las sustentan.

\section{Representación y realidad}

Pictóricamente es posible identificar diversos modos de representación, cada uno de los cuales construye de manera diferente la relación entre un espectador y una 
determinada imagen de realidad. Imaginemos un primer cuadro concebido como una ventana al mundo percibido. En este cuadro el artista se coloca en el mismo lado de la superficie pictórica que el observador y a través del marco mira un mundo que luego reconstruye sobre la superficie pictórica por medio de la convención geométrica de la perspectiva lineal. Este primer cuadro lo podemos representar tal como lo hace Durero en su obra de Un artista trabajando. En él vemos a una mujer que ofrece su cuerpo desnudo para que el artista, a través del marco de la rejilla, realice una representación fiel de lo que está observando. Podríamos hacer extensiva esta relación y decir que la modelo es la realidad que se ofrece al pintor para ser pintada. Es esta relación la que permite al artistaespectador decir "Yo veo la realidad" (ALPERS 8.: 1995,153-162).

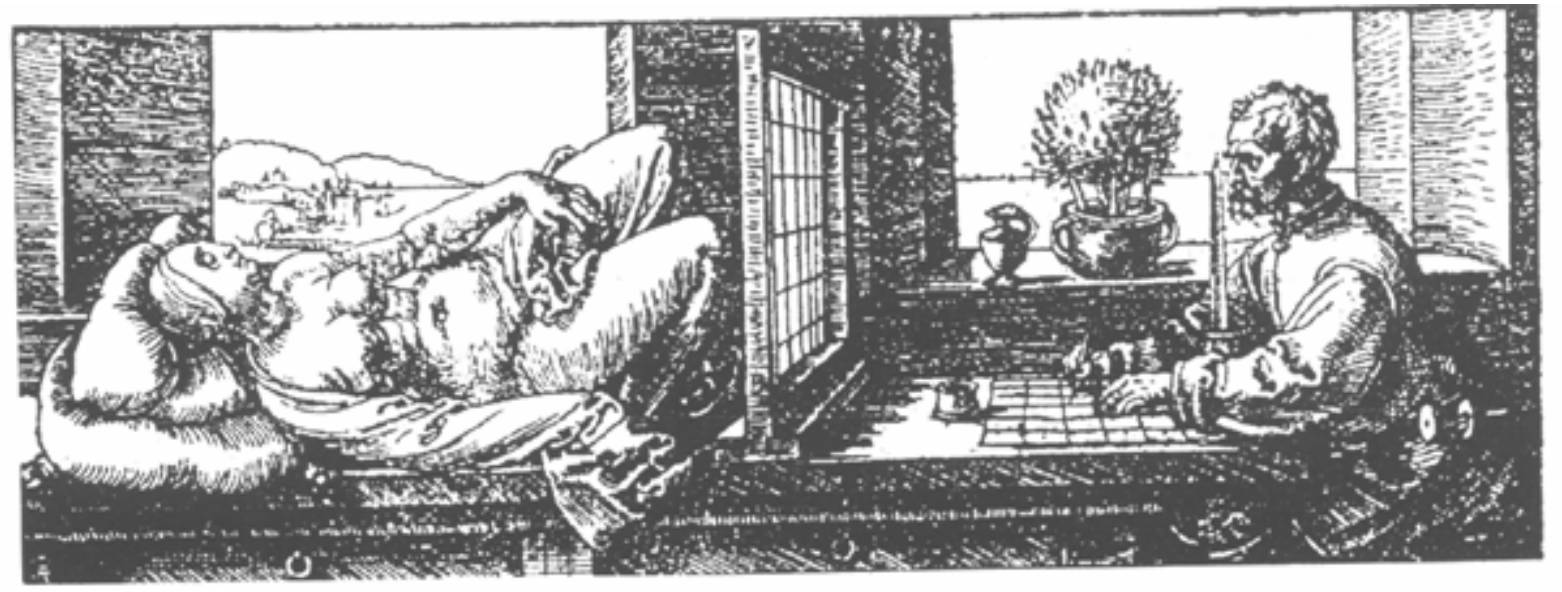

Un segundo cuadro no es una ventana sino más bien una superficie en la cual una imagen de la realidad se plasma por si misma, al igual que una luz enfocada por medio de una lente forma una imagen en la retina del ojo. En este cuadro en lugar de un artista que enmarca la realidad para representarla, la realidad produce su propia imagen sin necesidad de marco. Tal representación la vemos en la pintura holandesa Cámara Oscura del siglo XVII, en la que dos hombres, en un cuarto oscuro equipado con un agujero para dejar pasar la luz a través de una lente, sostienen una superficie sobre la cual se proyecta el paisaje exterior. En contraste con el hombre que "posee" mediante su arte a la mujer que observa, dos hombres contemplan la imagen preexistente de la realidad. Es esta relación la que permite decir a los hombres-espectadores "la realidad está siendo vista" (ALPERS S.: 1995, 158).

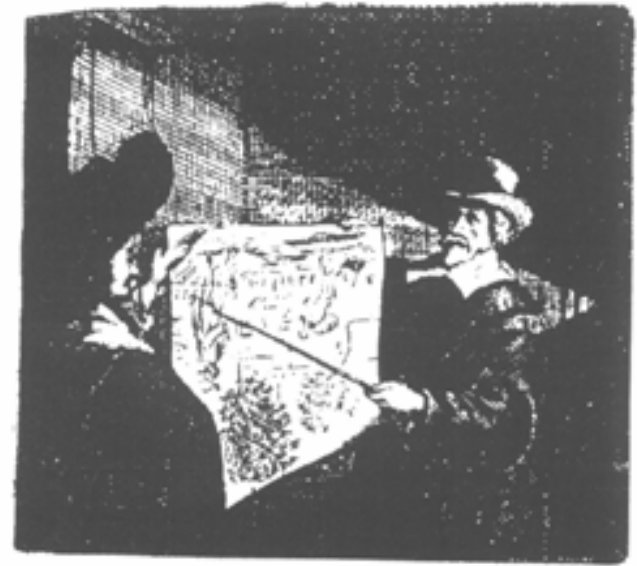


Estos dos modos de representación asumen la realidad como algo preexistente, independiente al sujeto, con un contenido y un sentido propio. Desde ellas se establece igualmente una dicotomía entre sujeto y objeto. "Uno supone la prioridad de un espectador frente al cuadro y el otro asume que la realidad es anterior a cualquier presencia humana y es, por tanto, esencialmente inconmensurable" (ALPERS S.: 1995, 160).

Un tercer cuadro no es una ventana al mundo percibido, ni una superficie en la que la realidad se refleja, sino un lugar de reciprocidad, un cara a cara, un cruce de miradas entre nosotros que vemos el cuadro y un pintor que nos contempla. Esta es una primera impresión que nos causa la desconcertante y a la vez la obra maestra del arte occidental:

Las Meninas de Diego Velázquez. La tradición pictórica reconoce en este cuadro una recreación de la corte española del siglo XVII. Velázquez compuso este cuadro en el que se ha representado así mismo, en su estudio o en un salón del Escorial, mientras pinta dos personajes que la infanta Margarita viene a ver, rodeada de dueñas, de meninas, de cortesanos y de enanos, .... este grupo puede atribuírsele nombres muy precisos,... se reconoce aquí a María Agustina Nieto Sarmiento, allá a Nieto, en el primer plano a Nicolaso Pertusato. El Bufón italiano. Bastará con añadir que los dos personajes que sirven de modelo al pintor no son visibles cuando menos directamente, pero se les puede percibir en un espejo; y que se trata, a no dudar, del rey Felipe IV y de su esposa Mariana (FOUCAULT M.:1988, 19).

Una segunda impresión que causan los personajes, los modelos, los espectadores, las imágenes que flotan en el espacio que configura el cuadro, es de desconcierto. En efecto, la pregunta que nos hacemos cuando contemplamos el cuadro es: ¿vemos? ¿o nos ven? La mirada nos confirma que los personajes dirigen su atención hacia un punto de la escena representada que está por fuera de la representación. Están observando el modelo que el pintor esta pintando y que aparece oculto a nuestra visión. El pintor, a su vez, con paleta en mano, contempla algún rasgo de sus modelos y se ocultará en cualquier momento para pintarlos, perdiéndose así de nuestra vista. Desconcertante el que en la representación que contemplamos no esté representado el objeto que es visto por los personajes de la representación.

En el fondo del cuadro hay dos cuadros colgados, uno de los cuales se destaca por su solitaria brillantez y que la tradición reconoce como un espejo. En el se refleja el modelo -Felipe IV y su esposa Mariana- que está siendo representado. Pero curiosamente ese espejo que nos muestra el objeto de la representación no es visible por ninguno de los personajes que están representados en la representación.

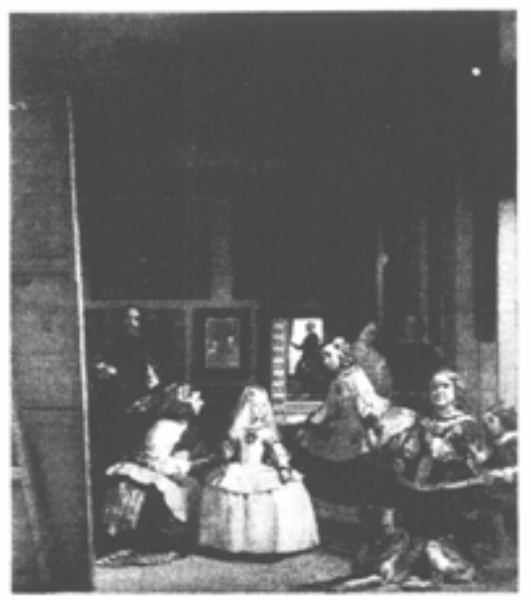


Esta sutil ambigüedad se refuerza con los lugares que espectadores y personajes ocupan en la representación. En efecto, el lugar que ocupa el modelo en ese plano pictórico que está por fuera de la representación, es ocupado por el espectador. De ahí la pregunta: ¿nosotros estamos viendo o estamos siendo vistos?

Tal vez sea esta incertidumbre de la visibilidad la que nos termina haciendo parte de la representación. Somos un personaje más de la escena que está siendo representada. En este sentido puede decirse que con este modo de representación la dicotomía entre el sujeto y el objeto se rompe y se configura una dialéctica sujeto-objeto desde la que cada uno de los dos se hace visible para el otro. Nosotros nos configuramos como sujetos de observación en la medida en que somos objetos observables. Es en ese juego dialéctico, en esa interrelación sujeto-objeto de donde surge y se configura el sentido de la realidad.

Esta Eco-Perspectiva, como veremos más adelante, es sumamente importante en un trabajo pedagógico. En efecto, independientemente de cual sea la postura epistemológica y filosófica desde la cual se piensa la realidad y las formas desde las cuales se considera que esa realidad tiene sentido, resulta relevante que se puedan desarrollar argumentos y hacer consciente nuestra perspectiva de asumir la realidad ya sea como objetiva o como construida. Es decir, de asumir una realidad independiente al sujeto, en la que el conocer se reduce a un descubrir y leer las marcas, los signos, las señales que configuran el sentido que ella tiene impreso o, una realidad dependiente del sujeto, en la que el conocer surge como resultado de una dialéctica entre el tipo de interacciones que los sujetos establecen con los objetos de su mundo

\section{Iconografía y representación de los seres vivos}

La "lectura" de algunas iconografías sobre lo vivo nos permite comprender el tipo de representaciones que sobre ellos se han elaborado, como también dar cuenta de las imágenes de conocimiento y de realidad que las sustentan.

Históricamente es posible identificar distintas representaciones sobre los seres vivos que se corresponden con una imagen de realidad y unas formas de relación HombreHombre, Hombre-Naturaleza. Si bien muchas de estas representaciones han sido históricamente superadas por la disciplina biológica, es interesante ver cómo ellas coexisten con posturas contemporáneas en muchos de nuestros contextos escolares. Por tal razón, un trabajo pedagógico debe permitir que se hagan explicitas esas representaciones de tal manera que estudiantes y maestros puedan construir argumentos para sustentar posturas conceptuales sobre dichas representaciones.

En este escrito se plantea que los fracasos de la Educación Ambiental, en nuestros contextos escolares, obedecen fundamentalmente, a la ausencia de un trabajo que permita valorar la importancia de hacer explícitas las representaciones que sobre los seres vivos se tienen. Igualmente es posible afirmar que el tipo de representaciones cotidianas que se poseen sobre los seres vivos, no favorece desarrollos en términos de cambios de actitudes, valoraciones o ejecución de proyectos para la conservación, manejo y cuidado del ambiente, entre otras, sino al contrario, genera obstáculos para transformar nuestras relaciones con el mismo.

Una primera representación presente en los primeros años de formación escolar y en los imaginarios cotidianos, es aquella según la cual se considera a los seres vivos como seres que nacen, crecen, se reproducen y mueren. Esta representación permite definir a 
los mamíferos, a las aves y a "todos los que se reproducen por medio de huevos", como seres vivos.

En efecto, en las aves el nacimiento hace referencia a salir de un cascarón y en los mamíferos a salir de un vientre. En estas dos formas lo vivo se entiende como algo que está contenido en un recipiente, el nacer como un dar a luz, el crecer como un aumentar de tamaño hasta alcanzar el estado adulto, el reproducir como una forma de dejar descendencia y el morir como la suspensión de toda manifestación de vida.

Usualmente esto es lo que en las clases de ciencias naturales se enseña a los niños. En la clase de ciencias sociales le dicen que el río Magdalena nace en la laguna La Magdalena, que crece y entonces le hablan de la "subienda", que se reproduce y entonces le hablan de afluentes y efluentes y que muere y entonces le hablan de la desembocadura de Bocas de Ceniza. Igualmente cuando estudian el universo le dicen cosas similares; que las estrellas nacen, crecen y que también mueren. El carácter indiferenciado de esta representación resultaría interesante si con ella se buscara desarrollar criterios que permita distinguir objetos; pero como usualmente esta intención está ausente en el maestro y lo que prima es "enseñar qué son los seres vivos, qué es un río o qué es una estrella", tal representación se queda en un nivel de ambigüedad que no permite a los niños y a los maestros hacer de las "cosas" que estudian, problemas de conocimiento. Desde esta representación un ser vivo es un ser vivo, un río es un río, una estrella es una estrella. Son obvios y evidentes de por sí. Basta con señalarlos con el dedo para saber que son y que es cada uno de ellos. Esta representación está ligada con algunas imágenes desde las cuales se considera la naturaleza y los seres vivos como creados y, al hombre como un ser privilegiado hecho a imagen y semejanza de Dios. Tal representación, que podemos denominar mítica o religiosa, no sólo considera a la naturaleza como resultado de un acto divino de creación, sino que también ve la realidad como algo inmanente y como tal con un sentido y un significado independiente a los sujetos.

De esta concepción se derivan varias prácticas educativas. En primer lugar que el hombre se asuma como puesto en la naturaleza y que todo lo que hay en ella esté para su provecho y beneficio; en segundo lugar, que las prácticas educativas se circunscriban a la simple ordenación y clasificación de los seres en grupos taxonómicos y por último que las relaciones Hombre-Naturaleza se reduzcan a la contemplación de las causas que determinan su belleza y armonía. Esta representación exteriorista de los seres vivos hace infructuoso el desarrollo de propuestas en Educación Ambiental que buscan constituir a los sujetos en agentes transformadores de las relaciones con su medio natural y social. Igualmente, es posible mencionar otro tipo de representación sobre los seres vivos que, sin dejar de verlos como seres creados, se preocupa por estudiarlos en términos de su estructura visible. Es decir, se preocupa por describir sus partes y la manera como ellas están dispuestas en un todo.

El siguiente grabado nos muestra al cuerpo humano constituido como un libro abierto en el que se busca indagar por lo que aparece oculto a la visión. Con la disección, el cuerpo se abre hoja a hoja tratando de revelar esa arquitectura oculta a los ojos, que hace a cierta estructura aparecer como un todo armónico. Pero el grabado también muestra que el interés del naturalista de los siglos XVII y XVIII es describir lo que aparece visible a nuestra vista: líneas, superficies, formas, relieves. Estos constituirán los objetos filtrados que harán accesible el análisis de la Estructura Visible de los seres vivos y desde los cuales la Historia Natural fundará el campo de su visibilidad y definirá el límite a partir del cual plantas y animales pueden ser estudiados. En esta nueva configuración "ver" 
significará sólo eso: observar las cosas tal cual aparecen ante los ojos, es decir en su forma simple, clara y distinta; con tal criterio, plantas y animales aparecen ante los ojos en su forma más simple, en su extensión. Así, la Historia Natural será «la posibilidad de ver lo que se podrá decir, pero que no se podría decir en consecuencia ni ver a distancia si las cosas y las palabras, distintas unas de otras no se comunicaran en el inicio del juego en una representación" (FOUCAULT M.: 1988, 130); representación que, a través de la descripción, de la utilización de formas y relieves, dará cuenta de la composición y disposición de las partes de las plantas y animales. La denominación de esta visibilidad, que los botánicos llamaron estructura, constituye el campo desde el cual la Historia Natural, a partir del siglo XVII elaborará un lenguaje fundamentalmente taxonómico de los seres vivos.

Es este lenguaje, esta semántica la que da forma y sentido al mundo de los seres vivos hasta comienzos del siglo XIX y es la transformación de este lenguaje, de esta semántica la que se nos aparece como lo que permitirá acceder a ellos desde una consideración muy distinta a la de su visibilidad: la de la vida misma. Para esto es necesario inventar "nuevas palabras que respondan a conceptos nuevos y, de hecho, a objetos nuevos: por ejemplo lo que se denomina organización" (SENET-JOSA J.: 1975, 53). Sin embargo, la organización no se entiende aquí como la complejidad de la estructura visible, tal y como se pensaba en los siglos XVI y XVII, sino como una cualidad particular llamada vida, desde la cual se trata de establecer la relación de lo que se ve con lo que no se ve y, con la que es posible, además, decidir entre lo que es viviente y lo que no lo es.

Así, desde finales del siglo XVIII lo importante no es establecer diferencias entre la estructura de los vivientes, sino determinarlo que existe de común entre ellos y que los diferencia de los no vivientes; surgen de esta forma dos categorías para clasificar los objetos de este mundo: lo orgánico y lo inorgánico; lo primero corresponderá entonces a lo viviente y con ello se intentará determinar relaciones de estructura y función entre órganos aparentemente disímiles como las alas de un pájaro y los miembros superiores de los mamíferos.

O de manera más específica, la referencia a la función hace aparecer nuevas relaciones, como las de coexistencia, jerarquía interna y de dependencia con respecto a un plan de organización, desde las cuales el ser vivo adquirirá una significación renovada.

En efecto, desde el análisis de estas relaciones, por ejemplo, en el sistema digestivo, la forma de los dientes (el que sean afilados o masticadores) varia al mismo tiempo que el largo, las dilataciones y los repliegues del tubo digestivo. En general, los órganos digestivos no pueden variar con independencia de la morfología de los miembros y en particular de la forma de las uñas; según sean cascos o zarpas, los jugos digestivos y la forma de los dientes no serán los mismos. Como ilustran los grabados, los hipopótamos jirafas (arriba) que al parecer son herbívoros tendrán dientes planos y cascos y, el carnicero Megalania (abajo), dientes afilados y garras.

Dicho análisis también permite establecer la prelación que hay entre una función y otra. "Cuvier pensó primero que las funciones de existencia eran anteriores a las de la relación, pues [según él] el animal es primero después siente y actúa” (FOUCAULT M.:1988, 261). Con esta representación la noción de funciones vitales y su relación con la estructura visible se convierte en el centro de preocupación de análisis de los seres vivos. Es decir se centra la atención en el estudio de las grandes funciones - nutrición, respiración, circulación, reproducción, excreción- que en su conjunto, en el tipo de interrelaciones que se dan en ellas, hace posible que se manifieste el fenómeno de la vida. A los seres 
que manifiestan esta propiedad se denominan seres vivos y la ciencia que estudia estos seres organizados, como se les empezará a denominar, se llamará Biología.

Esta representación es muy difundida en las prácticas educativas desde la cual se amplía el límite de la estructura visible a la descripción de las grandes funciones, y se refuerza su análisis con la introducción de la noción de equilibrio, entre el "medio externo" y el "medio interno" del organismo. En este ámbito cobran relevancia los discursos sobre desarrollo sostenible que asumen una permanente tensión de la explotación del medio y una posible conservación de un equilibrio cuasi-estático.

Desde esta perspectiva la educación ambiental trata de generar en los individuos una serie de actitudes tendientes a reducir al mínimo su impacto sobre el medio, que en últimas se traduce en la realización de campañas de reciclaje, arborización, entre otras, sin que medie una actitud reflexiva y crítica sobre las prácticas cotidianas y económicas que realmente inciden en el deterioro del medio ambiente; así mismo, estas prácticas se circunscriben a un estudio de las relaciones hombre-medio natural, donde el medio natural es lo que está por fuera, el recipiente donde están los seres vivos y no el espacio de relaciones del cual hace parte constitutiva y como tal el espacio desde donde se configura como sujeto.

Esta representación sobre los seres vivos y el ambiente es la que orienta con mayor énfasis las prácticas educativas en Educación Ambiental en nuestro medio. Sin lugar a dudas, podemos afirmar que las acciones que se desarrollan desde ella constituyen un simple paliativo que no tiene una incidencia significativa en la transformación de las relaciones Hombre-Hombre, Hombre-Naturaleza.

Una última representación que podemos mencionar, es solidaria con los desarrollos de la ciencia contemporánea en torno a la caracterización de la noción de sistema como elemento de comprensión de los fenómenos que acontecen en el universo; así, considerar que la materia se configura en entidades cada vez más complejas donde las partes se cohesionan y comparten el mismo destino, permite acceder a un nuevo nivel de comprensión de los seres vivos donde acaba la preeminencia de lo vivo sobre lo no vivo y se desdibujan los límites entre ser vivo y entorno, inaugurándolas como nociones mutuamente constitutivas (FORERO J.C. y MENDEZ O. M.: 1977).

Desde esta perspectiva, desaparece la escisión entre ser vivo y entorno. En efecto, pensar el ser vivo como unidad sistémica implica aproximarse a determinar ". . . la formación de redes de reacciones moleculares.. .que limitan el entorno espacial en que se realizan" (MATURANA H y VARELA F.:1996, 33) y a especificar las relaciones que tienen lugar ... en un medio que constituye el entorno.., y en el cual interactúa y que nosotros también vemos como dotado de una dinámica estructural propia, operacionalmente distinta del ser vivo" (MATURANA H y VARELA F.:1996,81).

Es decir, nos vemos abocados a comprender las relaciones dinámicas que permiten a una entidad construir los elementos de los que está constituida, establecer límites y diferenciarse de su entorno como una unidad autónoma e independiente. Desde esta perspectiva, igualmente, nos vemos obligados a considerar el ser vivo como una organización que tiene sentido más allá de un cuerpo y se hace posible a partir de las interacciones "ser vivo-entorno"; e "ser" entonces deja de ser un concepto por abstracción de su entorno y se hace perentorio entonces inaugurar la categoría de ecosistema. Como tal no podemos sustraerlo para estudiarlo y conceptualizarlo fuera de su espacio, pues nos estaríamos perdiendo la comprensión de la pluralidad de relaciones que lo hacen 
posible. De esta manera, la noción misma de "ser vivo" pierde su sentido en tan-toque se desplaza el estudio de sus partes y la descripción de sus funciones, por el análisis de las relaciones que lo han hecho posible. Trascendemos el ser y nos vinculamos a su devenir. Es decir, nos vemos abocados a comprender los procesos físico-químicos que configuran su emergencia, su permanencia y su transformación en el tiempo.

Una perspectiva sistémica de este corte, igualmente, considera que las relaciones del hombre, consigo mismo, y con sus congéneres, no están determinadas por una inteligencia exterior a ellos sino que se establecen por el libre juego de lo posible, en donde el papel de la conciencia asignada a la condición humana, como emergencia, le provee de unas responsabilidades éticas, políticas, ideológicas y educativas, que van más allá de las prescripciones que derivan de acciones esporádicas e intrascendentes de las 'campañas ambientalistas'.

Estamos hablando de la necesidad, desde esta representación, de la configuración de una ética civil capaz de considerar al hombre y al resto de la naturaleza como emergencias de relaciones y de la Educación Ambiental como una estrategia pedagógica capaz de redimensionar los imaginarios, las conceptualizaciones, las valoraciones y las actitudes, que determinan las relaciones Hombre-Hombre, Hombre-Naturaleza.

Con esta noción del "ser vivo" como sistema y del hombre como emergencia biológica y cultural, cabe plantearse la siguiente pregunta: ¿Cómo puede la Educación Ambiental - siendo un saber que hace parte de la cultura- hacer del vivir del hombre contemporáneo algo cualitativamente diferente?

\section{TERCERA ECO-PERSPECTIVA: LA EDUCACIÓN AMBIENTAL COMO PROYECTO DE VIDA}

Las anteriores Eco-perspectivas, desde las cuales se considera el ser vivo y los ecosistemas como emergencias de relaciones, nos muestran posibilidades conceptuales para ensanchar nuestra imagen de ambiente y ver a este como el resultado de múltiples interacciones. Como tal es posible hablar entonces no solo del mundo natural, en el sentido tradicional del término, sino también del ámbito social y del ámbito personal como ambientes.

Es posible entonces hablar de la configuración de una Ecosofía (GUATTARI F.: 1996) desde la cual podamos comprender las complejas relaciones que hacen posible, por ejemplo, los enigmas de una laguna, las incertidumbres de las relaciones sociales, o las cartografías de la subjetividad humana. En este marco de ideas la Educación Ambiental cobra significado en tanto y en cuanto busca de manera deliberada y consciente incidir sobre las relaciones Hombre-Hombre, Hombre-Naturaleza.

Es decir, en la medida en que indaga por las concepciones, significados y valoraciones que los sujetos poseen sobre lo vivo, sobre sí mismo y sobre sus congéneres, de tal manera que permita redimensionar y articular las acciones que bajo la categoría "ambiental" se desarrollan en los contextos escolares, al igual que proyectar las intenciones de maestros y estudiantes "ambientalistas" al enriquecimiento de las relaciones Educación-Ciudad. 


\section{BIBLIOGRAFÍA}

ALPERS, Svetlana. "Interpretación sin representación: Mirando las Meninas". En: MARIAS Fernando (Edi.). Otras Meninas. 1995. Ediciones Siruela. Madrid. Pp. 153-162.

BEN-DOV, Yoav. "Modelos de conocimiento y estrategias de educación". En: Rey. Planteamientos en Educación. Vol. 3. № 1. Jul. 1998. Pp. 69-89.

ELKANA, Y. La ciencia como sistema cultural: una aproximación antropológica. Boletín Sociedad Colombiana de Epistemología, 1983. FORERO J.C. MENDEZ O.M. ¿Los seres vivos como sistemas dinámicos? Ensayo presentado en la Componente de Biología. Especialización en Docencia de las Ciencias. U.RN. Bogotá. 1997.

FOUCAULT Michel. Las palabras y las cosas. Planeta-Agostini. 1984. Barcelona.

GUATTARI, F. Las tres ecologías. Pre-textos. Valencia. 1996.

MATURANA, H. y VARELA, F. El árbol del conocimiento. Ed. Debate. Madrid. 1996, p. 33.

SENET-JOSA, Joan. "Entrevista a François Jacob". En: Lógica de lo viviente e historia de la biología. Barcelona. Anagrama. 975, p. 53. 